\title{
Article \\ Endothelium-Derived Hyperpolarizing Factor (EDHF) Mediates Acetylsalicylic Acid (Aspirin) Vasodilation of Pregnant Rat Mesenteric Arteries
}

\author{
Helga Helgadóttir ${ }^{1,2}$, Teresa Tropea ${ }^{1}$, Sveinbjörn Gizurarson ${ }^{2}$ (D) and Maurizio Mandalà $1, *(D)$ \\ 1 Department of Biology, Ecology and Earth Sciences, University of Calabria, Arcavacata di Rende, \\ 87036 Cosenza, Italy; helgadottir@hi.is (H.H.); teresa.tropea@manchester.ac.uk (T.T.) \\ 2 Faculty of Pharmaceutical Sciences, University of Iceland, Hofsvallagata 53, 107 Reykjavik, Iceland; \\ sveinbj@hi.is \\ * Correspondence: m.mandala@unical.it
}

check for updates

Citation: Helgadóttir, H.; Tropea, T.; Gizurarson, S.; Mandalà, M.

Endothelium-Derived

Hyperpolarizing Factor (EDHF)

Mediates Acetylsalicylic Acid (Aspirin) Vasodilation of Pregnant Rat Mesenteric Arteries. Int. J. Mol. Sci. 2021, 22, 10162. https://doi.org/ 10.3390/ijms221810162

Academic Editor: Guido Iaccarino

Received: 30 August 2021

Accepted: 16 September 2021

Published: 21 September 2021

Publisher's Note: MDPI stays neutral with regard to jurisdictional claims in published maps and institutional affiliations.

Copyright: (c) 2021 by the authors. Licensee MDPI, Basel, Switzerland. This article is an open access article distributed under the terms and conditions of the Creative Commons Attribution (CC BY) license (https:/ / creativecommons.org/licenses/by/ $4.0 /)$.

\begin{abstract}
Acetylsalicylic acid (aspirin) exhibits a broad range of activities, including analgesic, antipyretic, and antiplatelet properties. Recent clinical studies also recommend aspirin prophylaxis in women with a high risk of pre-eclampsia, a major complication of pregnancy characterized by hypertension. We investigated the effect of aspirin on mesenteric resistance arteries and found outdiscovered the molecular mechanism underlying this action. Aspirin $\left(10^{-12}-10^{-6} \mathrm{M}\right)$ was tested on pregnant rat mesenteric resistance arteries by a pressurized arteriography. Aspirin was investigated in the presence of several inhibitors of: (a) nitric oxide synthase (L-NAME $2 \times 10^{-4} \mathrm{M}$ ); (b) cyclooxygenase (Indomethacin, $10^{-5} \mathrm{M}$ ); (c) $\mathrm{Ca}^{2+}$-activated $\mathrm{K}^{+}$channels (Kca): small conductance (SKca, Apamin, $10^{-7} \mathrm{M}$ ), intermediate conductance (IKca, TRAM34, $10^{-5} \mathrm{M}$ ), and big conductance (BKca, paxilline, $10^{-5} \mathrm{M}$ ); and (d) endothelial-derived hyperpolarizing factor (high $\mathrm{KCl}, 80 \mathrm{mM}$ ). Aspirin caused a concentration-dependent vasodilation. Aspirin-vasodilation was abolished by removal of endothelium or by high $\mathrm{KCl}$. Furthermore, preincubation with either apamin plus TRAM-34 or paxillin significantly attenuated aspirin vasodilation $(p<0.05)$. For the first time, we showed that aspirin induced endothelium-dependent vasodilation in mesenteric resistance arteries through the endothelial-derived hyperpolarizing factor (EDHF) and calcium-activated potassium channels. By activating this molecular mechanism, aspirin may lower peripheral vascular resistance and be beneficial in pregnancies complicated by hypertension.
\end{abstract}

Keywords: endothelial cells; smooth muscle cells; relaxation; pre-eclampsia; hypertension; calciumactivated potassium channels

\section{Introduction}

The use of aspirin has been growing over the past decades. Initially, it was used as an analgesic, anti-inflammatory, and antipyretic drug, as well as an antiplatelet agent due to its ability to inhibit platelet aggregation [1,2]. Recently, aspirin has been suggested for use in pregnancy with high cardiovascular risk to prevent the development of gestational hypertensive disorders, such as pre-eclampsia (PE) [3,4]. PE is a major complication of pregnancy and is one of the leading causes of maternal and perinatal morbidity and mortality [5]. Currently, there is no cure for PE; the most effective management of the disease is delivery [6], which can worsen neonatal outcomes if it needs to be initiated early in pregnancy. Therefore, early-onset PE requires treatments that prevent preterm birth to enable optimal intrauterine fetal growth [6].

Clinical studies investigating the benefits of administering aspirin in PE produce contradictory results. In all likelihood, it is due to the different gestation period that aspirin treatment was initiated and also to the different doses used. In fact, the benefit of aspirin was only observed in clinical studies that initiated aspirin treatment before the 16th week 
of pregnancy and at low- and mid-dose [7]; in contrast, aspirin in late pregnancy and at a high dose did not show beneficial effect [8]. However, the mechanisms through which aspirin acts remain unclear. Few studies have suggested a beneficial effect of aspirin on endothelial function, vascular activity, and a possible overall positive effect on the vascular system [9-15].

In normal pregnancy, the maternal vasculature undergoes a significant change [16] to meet the needs of the placental-fetal growth, including a reduction in the total peripheral vascular resistance (PVR) [17]. On the other hand, PE is characterized by an increase in PVR as a consequence of endothelial dysfunction [18]. The endothelium, the inner layer of the blood vessels, plays an important role in the regulation of the vascular tone by the release of several relaxing and contracting factors that act on the nearby smooth muscle cells $[19,20]$. In PE, an imbalance between the endothelial-derived factors, named endothelial dysfunction, has been reported [21], associated with microcirculatory disorder [22,23].

Vascular studies of PE are often carried out on the mesenteric vasculature, since it contributes significantly to the total PVR in pregnancy. In this study, we used mesenteric resistance arteries (MAs) from pregnant rats to investigate the effect and the mechanism of action of aspirin on the systemic vasculature. Our results show, for the first time, the molecular mechanisms that underlie aspirin vasodilation of mesenteric arteries, and suggest the splanchnic circulation as a possible target and aspirin benefit in hypertensive disorders of pregnancy.

\section{Results}

Aspirin was tested on preconstricted MA and induced a dose-dependent vasodilation, reaching $62 \pm 11 \%$ at the highest concentration of $10^{-6} \mathrm{M}$. Meanwhile, the vehicle for aspirin, ethanol, induced much less vasodilation $\left(22 \pm 6 \%\right.$, at $\left.10^{-6} \mathrm{M}\right)$, which was statistically different compared to the vasodilation caused by aspirin $(p<0.001$, Figure 1$)$.

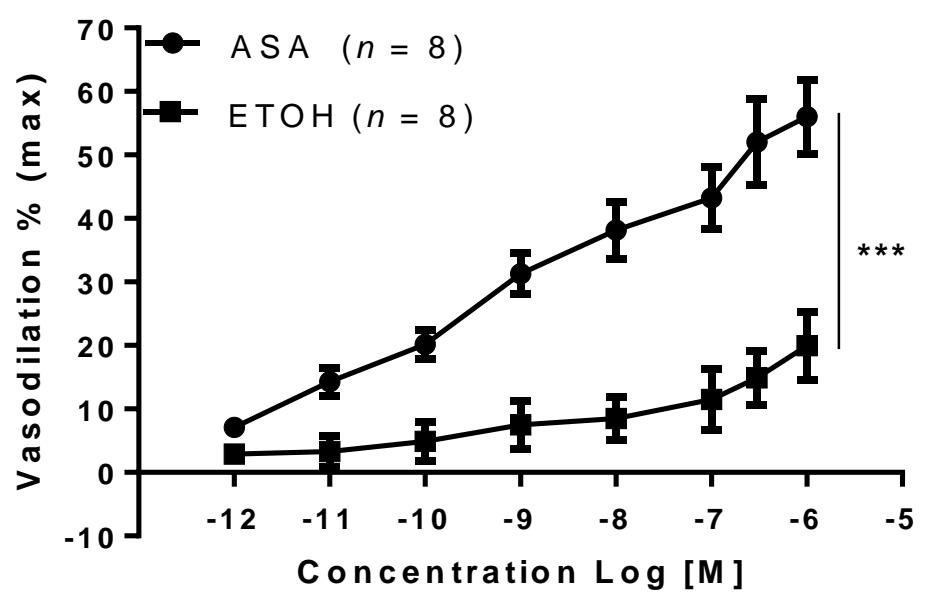

Figure 1. Acetylsalicylic acid vasodilation on mesenteric arteries. Acetylsalicylic acid (ASA) and its vehicle ethanol $(\mathrm{ETOH})$ were tested on phenylephrine preconstricted mesenteric arteries isolated from gravid rats. Data are reported as mean $\pm \mathrm{SEM}, n=$ number of experiments, ${ }^{* * *} p<0.001$ (two-way ANOVA).

To determine whether the endothelium was involved in the aspirin vasodilation, a dose-response to aspirin was carried out on both intact and denuded MA. Interestingly, removal of the endothelium completely abolished the vasodilation in response to aspirin (Figure 2). 


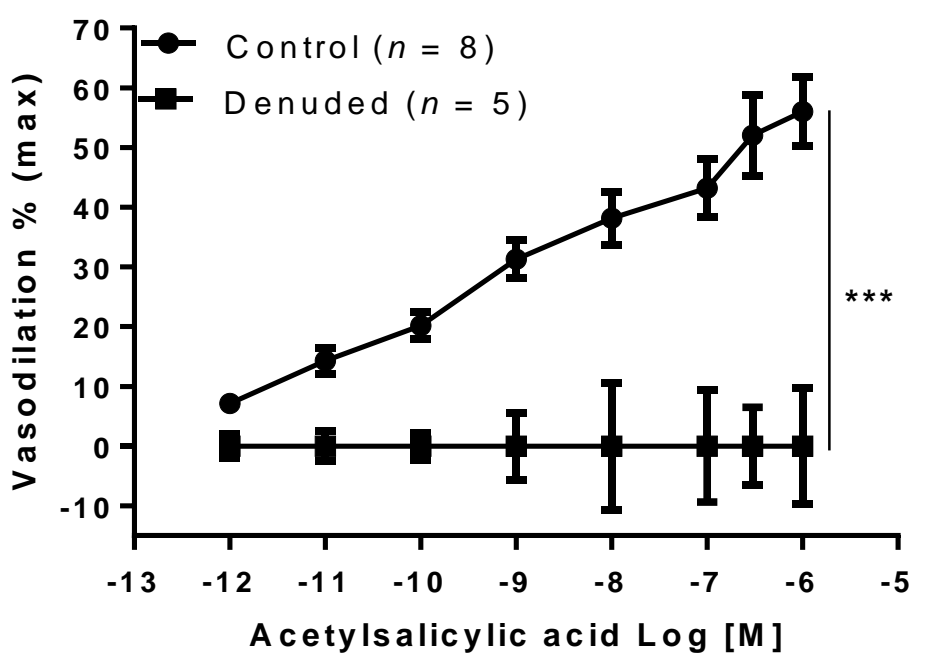

Figure 2. Acetylsalicylic acid effect on entire and denuded mesenteric arteries. Acetylsalicylic acid was tested on phenylephrine preconstricted mesenteric arteries entire (Control) and without endothelium (Denuded) isolated from gravid rats. Data are reported as mean \pm SEM, $n=$ number of experiments. ${ }^{* * *} p<0.001$ (two-way ANOVA).

Then, to determine the endothelial-derived relaxation factors involved in the vasodilation of aspirin, it was tested in the presence of inhibitors of NOS (L-NAME, $2 \times 10^{-4} \mathrm{M}$ ) and COX (indomethacin, $10^{-5} \mathrm{M}$ ). Vasodilation to aspirin was not affected by either LNAME or indomethacin (Figure 3).

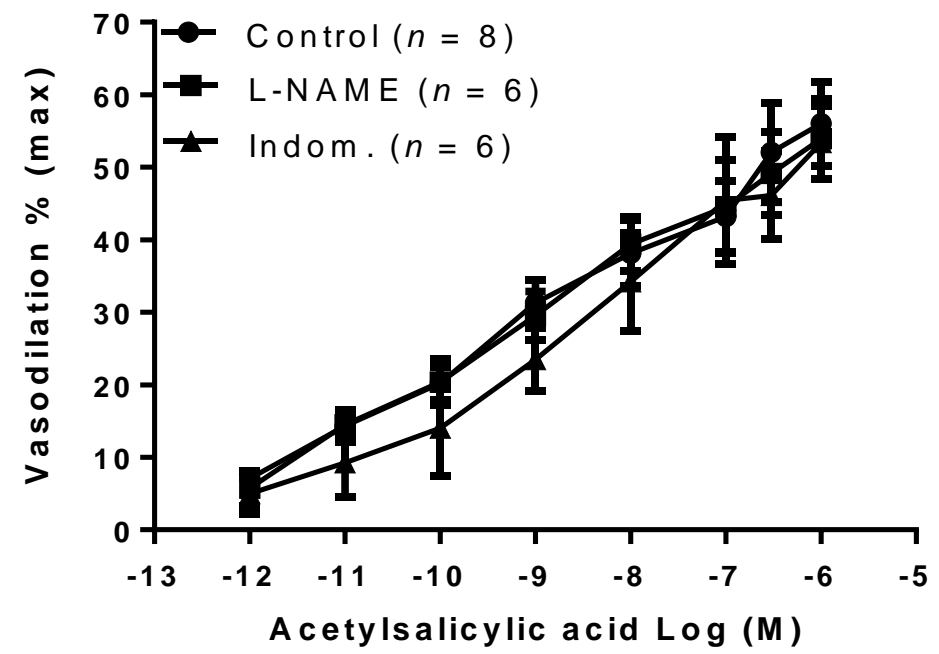

Figure 3. Effect of acetylsalicylic acid in the presence of nitric oxide synthase and cyclooxygenase inhibitors. Acetylsalicylic acid was tested on phenylephrine preconstricted mesenteric arteries isolated from gravid rats in the absence (Control) and in the presence of inhibitors of either nitric oxide synthase (L-NAME, $2 \times 10^{-4} \mathrm{M}$ ), or cyclooxygenase (Indom., $10^{-5} \mathrm{M}$ ). Data are reported as mean $\pm \mathrm{SEM}, n=$ number of experiments.

To find out if the EDHF was involved in aspirin vasodilation, MA were preconstricted with high $\mathrm{KCl}(80 \mathrm{mM})$, which completely abolished the vasodilator effect of aspirin $(p<0.001$, Figure 4). 


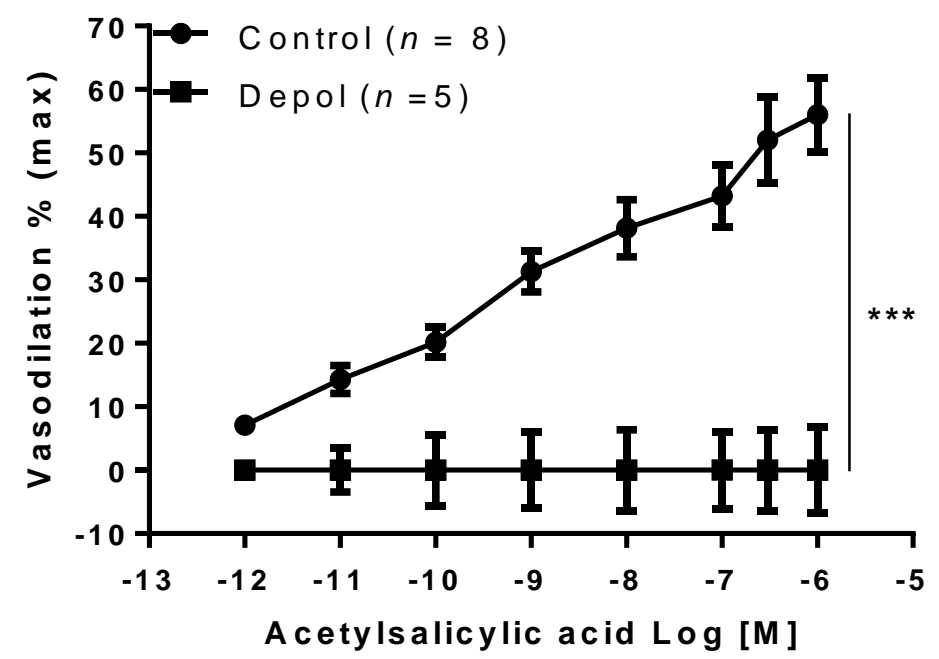

Figure 4. Effect of acetylsalicylic acid on preconstricted arteries. Acetylsalicylic acid was tested on mesenteric arteries isolated from gravid rats, preconstricted with phenylephrine (Control) or with high $\mathrm{KCl}(80 \mathrm{mM})$, which induces depolarization (Depol). Data are reported as mean $\pm \mathrm{SEM}$, $n=$ number of experiments, ${ }^{* * *} p<0.001$ (two-way ANOVA).

In addition, vasodilation to aspirin was significantly reduced following pre-incubation with apamin $\left(10^{-7} \mathrm{M}, p<0.05\right)$ and TRAM-34 $\left(10^{-5} \mathrm{M}, p<0.05\right)$ blockers of SKca and IKca channels, respectively (Figure 5).

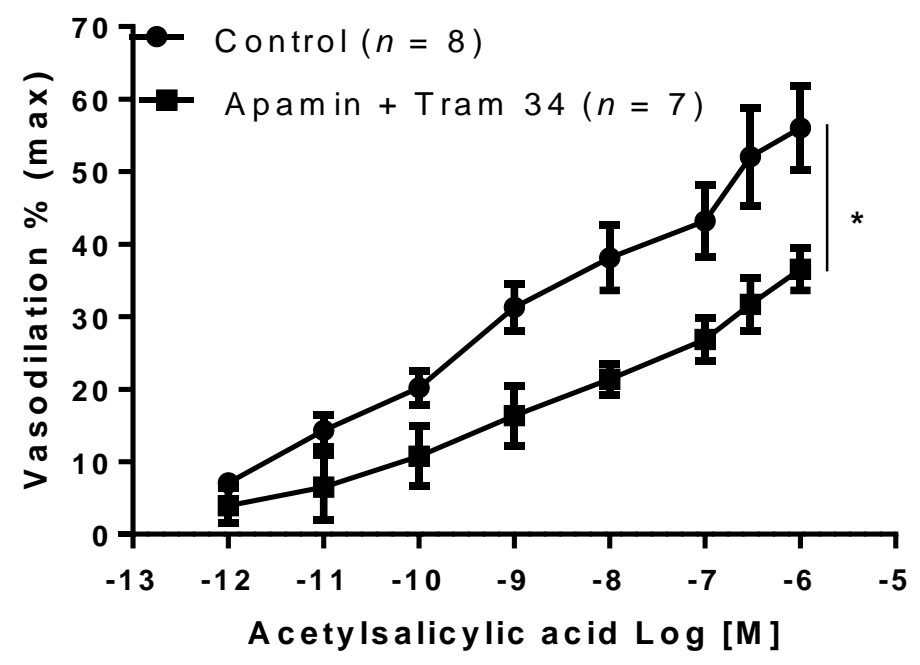

Figure 5. Effect of acetylsalicylic acid in the presence of calcium-activated potassium channel inhibitors. Acetylsalicylic acid was tested on phenylephrine preconstricted mesenteric arteries isolated from gravid rats in the absence (Control) or in the presence of both calcium-activated potassium channel small $\left(\mathrm{Sk}_{\mathrm{Ca}}\right.$ ) and intermediate $\left(\mathrm{IK}_{\mathrm{Ca}}\right)$ inhibitors Apamin $\left(10^{-7} \mathrm{M}\right)$ and TRAM-34 $\left(10^{-5} \mathrm{M}\right)$, respectively. Data are reported as mean $\pm \mathrm{SEM}, n=$ number of experiments, ${ }^{*} p<0.05$ (two-way ANOVA).

Furthermore, additional experiments demonstrated that vasodilation was significantly reduced in MA preincubated with the BKca channel inhibitor, paxillin $\left(10^{-5} \mathrm{M}, p<0.05\right.$, Figure 6). 


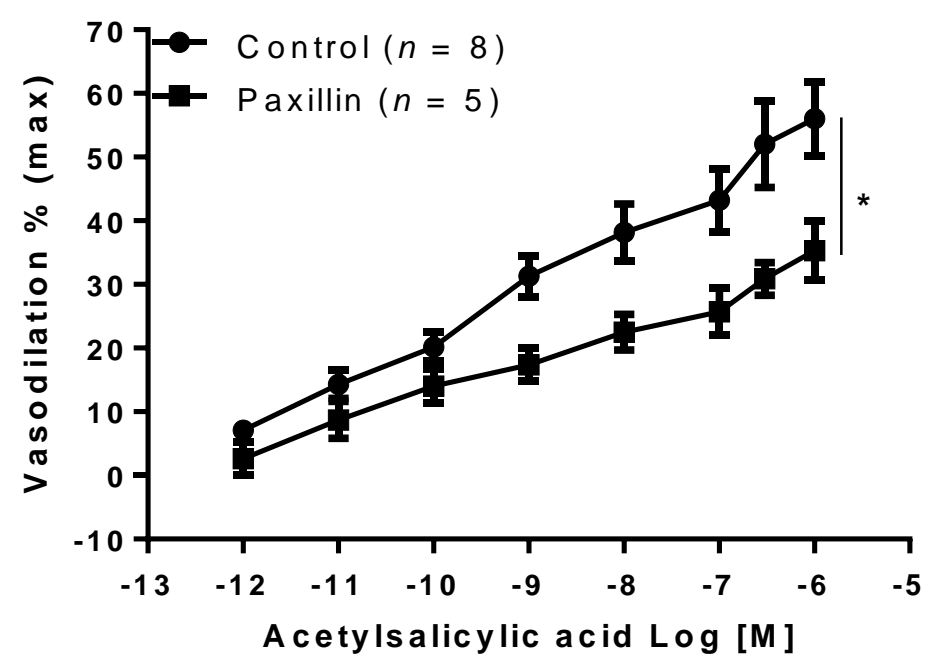

Figure 6. Effect of acetylsalicylic acid in the presence of BKca channel inhibitor. Acetylsalicylic acid was tested on mesenteric arteries isolated from gravid rats in the absence (Control) or in the presence of big potassium channel (BKca) inhibitor (paxillin, $10^{-5} \mathrm{M}$ ). Data are reported as mean $\pm \mathrm{SEM}$, $n=$ number of experiments, ${ }^{*} p<0.05$ (two-way ANOVA).

\section{Discussion}

This study demonstrates that aspirin is a potent vasodilator of resistance MA isolated from pregnant rats, and it acts in a dose-dependent manner. The maximum vasodilation of about $62 \%$ was achieved at $10^{-6} \mathrm{M}$, although the relaxation effect was already observed at a very low concentration of $10^{-11} \mathrm{M}$, suggesting a high sensitivity of MA to aspirin.

Our results demonstrated that aspirin vasodilation of MA is endothelium-dependent, is mediated by the EDHF, and involves the calcium-activated potassium channels, SKca, IKca, and BKca.

Our data on aspirin vasodilation effect agree with previous studies in small uterine arteries (UA) [13], as well as in rat aortic rings [11], suggesting that aspirin acts on both resistance and conduit arteries. Small resistance arteries play an important role in the regulation of the blood flow to the organs, contributing to the total PVR, whose changes strongly influence blood pressure [24].

We carried out the experiments on resistance MA, which contributes significantly to total PVR since the mesenteric circulation receives approximately one third of cardiac output [25].

Our results demonstrate that aspirin vasodilation of MA is completely endotheliumdependent, since denuded MA were unresponsive to aspirin. This finding is in conformity with a previous work on UA [13]. However, in UA, aspirin vasodilation was mediated by nitric oxide (NO) and prostacyclin (PGI2) pathways, while, in MA, it occurred via activation of EDHF. These differences in the two types of vascular beds, one reproductive and the other systemic, suggest a vascular region dependency for the mechanisms underlying the aspirin vasodilation. Our results highlight the important role of EDHF in the aspirin vasodilation of resistance MA, in agreement with studies showing that EDHF is the major mediator of dilatation in the mesenteric vascular bed from pregnant rats [26], while, in UA, vasodilation is mainly mediated by $\mathrm{NO}$ [27].

Interestingly, EDHF vasodilation is reduced in complicated pregnancy, such as PE [28], with consequent increases in PVR, a hallmark of hypertension [29-33]. Therefore, on the basis of our results, we speculate that aspirin may benefit pregnancy with hypertension through lowering peripheral vascular tone by activating EDHF.

Several candidate molecules have been proposed for EDHF, such as cytochromeP450-derived arachidonic acid metabolite [34] myoendothelial gap junctions [35] and $\mathrm{K}^{+}$ channels [36]. In microcirculatory vascular beds, it is generally accepted that endothelial $\mathrm{SK}_{\mathrm{ca}}$ and $\mathrm{IK}_{\mathrm{ca}}$ play a pivotal role in mediating EDHF effects [37]. 
Our results showed that aspirin effect was reduced by the inhibition of $\mathrm{SK}_{\mathrm{ca}}$ and $\mathrm{IK}_{\mathrm{ca}}$, suggesting that the activation of those channels is involved in aspirin vasodilation of MA. Although, in the present study, the contribution of each channel was not studied, this possibility requires further investigation.

In addition, we also showed the involvement of BKca channels in the aspirin vasodilation, since it was reduced by the inhibitor paxillin. This can be interpreted by the support of the EDHF being the molecule that activates smooth muscle cell BKca channels, leading to hyperpolarization and vasodilation.

The Kca channels have been reported to be involved in the hyperpolarization and vasodilation of mesenteric arteries [38,39]. This is in agreement with our results, showing that aspirin vasodilation was completely inhibited by depolarization induced by high potassium chloride.

\section{Materials and Methods}

\subsection{Animals}

All experiments were conducted in accordance with the '3R principles' (www.nc3rs. org.uk, accessed on 24 February 2017) to reduce the number of animals and to optimize experimental protocols for obtaining maximum data from each tested animal, and with the European Guidelines for the care and use of laboratory animals (Directive 2010/63/EU). The arteries were isolated from animals used in a study approved by the local ethical committee at the University of Calabria and the Italian Ministry of Health (n.74/2018-PR).

Sprague-Dawley 12-14-week-old gravid rats at term (20 days of gestation) were used in the experiments. Animals were housed at a temperature-controlled condition of $22{ }^{\circ} \mathrm{C} \pm 2{ }^{\circ} \mathrm{C}$ and under a 12-h light/dark cycle; food and water were provided ad libitum. Females were bred overnight in isolated pairs by the placement of a male rat. If a seminal plug was observed the following morning, the first day of pregnancy was confirmed.

The animals were first euthanized with isoflurane (4\%) and then decapitated; once dead, the abdominal cavity was opened and the entire mesentery was dissected and placed in a Petri dish containing cold $\left(4^{\circ} \mathrm{C}\right)$ HEPES physiological salt solution (HEPES-PSS).

\subsection{Vessel Preparation}

Arterial segments (2-3 mm) of mesenteric resistance arteries (MA, diameter $<300 \mu \mathrm{m}$ ) were obtained from rats. The segments were dissected free from connective and adipose tissue and transferred to a chamber of a small-vessel arteriography (Living Systems Instrumentation, St. Albans City, VT, USA). One end of the vessel was tied onto a glass cannula and flushed of any luminal content by increasing the pressure before securing the distal end onto a second cannula using a servo-null pressure system (Living Systems Instrumentation, St. Albans City, VT, USA). Before using the vessels for the experiments, the functionality of both smooth muscle and endothelial cells was tested, respectively, by high $\mathrm{KCl}(80 \mathrm{mM})$ and acetylcholine $\left(10^{-5} \mathrm{M}\right)$. The vessels that did not respond to both compounds were discarded.

\subsection{Experimental Protocol}

All vessels were continuously superfused with HEPES-buffered physiological saline solution (HEPES-PSS) at $37^{\circ} \mathrm{C}$ and $\mathrm{pH}$ 7.4. Each vessel was pressurized to $50 \mathrm{mmHg}$ (value that imitates in vivo conditions) and equilibrated for 45-60 min before the beginning of each experimentation. Lumen diameter was measured by transilluminating each vessel segment using a video dimension analyzer (Living Systems Instrumentation, St. Albans City, VT, USA) in conjunction with data acquisition software (Ionoptix, Westwood, MA, USA) to continuously record lumen diameter. Following equilibration, all vessels were preconstricted with phenylephrine to produce a $40-50 \%$ reduction in baseline diameter [40]. Once constriction was achieved and stable for about $10 \mathrm{~min}$, aspirin was added in the range of concentration of $10^{-12}$ to $10^{-6} \mathrm{M}$, and the resulting vasodilation was recorded. Moreover, 
ethanol (ETOH), as a vehicle of aspirin, was tested on phenylephrine-preconstricted artery at the same amount present in the range $10^{-12}-10^{-6} \mathrm{M}$ of aspirin.

Aspirin was tested in both intact and denuded (without endothelium) arteries. The endothelium was removed by air perfusion and the effectiveness of this procedure was confirmed by the absence of endothelium-dependent vasodilatation to acetylcholine $\left(10^{-5} \mathrm{M}\right)$.

To investigate the mechanism of action of aspirin, additional experiments were performed on intact arteries using: (a) Nw-nitro-L-arginine methyl ester (L-NAME, $2 \times 10^{-4} \mathrm{M}$ ) to block nitric oxide synthase (NOS); (b) indomethacin $\left(10^{-5} \mathrm{M}\right)$ to block cyclooxygenase (COX); (c) paxillin $\left(10^{-5} \mathrm{M}\right)$ to block $\mathrm{BK}_{\mathrm{Ca}}$ channels; (d) apamin $\left(10^{-7} \mathrm{M}\right)$ to block $\mathrm{Sk}_{\mathrm{Ca}}$ channels; (e) TRAM-34 $\left(10^{-5} \mathrm{M}\right)$ to block $\mathrm{IK}_{\mathrm{Ca}}$ channels; and (f) HEPES-PSS high $\mathrm{KCl}$ $(80 \mathrm{mM})$ to block endothelial-derived hyperpolarizing factor (EDHF) vasodilation. Vessels were preincubated with the inhibitors for $20 \mathrm{~min}$ before preconstriction with phenylephrine, and then aspirin was tested.

Aspirin vasodilation was expressed as percent of maximal diameter, which was determined at the end of each experiment in the presence of a relaxing HEPES-PSS solution containing diltiazem $(10 \mu \mathrm{M})$ and papaverine $(100 \mu \mathrm{M})$.

\subsection{Materials}

The physiological salt solution HEPES-PSS was freshly prepared for each experiment and comprised of: $\mathrm{NaCl}(141.8 \mathrm{mM}), \mathrm{KCl}(4.7 \mathrm{mM}), \mathrm{MgSO}_{4}(1.7 \mathrm{mM})$, EDTA $(0.5 \mathrm{mM})$, $\mathrm{CaCl}_{2}(2.8 \mathrm{mM})$, HEPES $(10.0 \mathrm{mM}), \mathrm{KH}_{2} \mathrm{PO}_{4}(1.2 \mathrm{mM})$, and glucose $(5.0 \mathrm{mM})$. The $\mathrm{pH}$ was adjusted to 7.4 at $37^{\circ} \mathrm{C}$ with $10 \mathrm{M} \mathrm{NaOH}$. In HEPES-PSS high $\mathrm{KCl}(80 \mathrm{mM})$, the composition was the same as HEPES-PSS, except for equimolar substitution of $\mathrm{KCl}$ for $\mathrm{NaCl}$.

Chemicals: phenylephrine, L-NAME, indomethacin, paxillin, apamin and all the above compounds for the HEPES-PSS preparationwere purchased from Sigma-Aldrich (Milan, Italy), while TRAM-34 was purchased from Abcam (Cambridge, UK). Acetylsalicylic acid (aspirin, Rhodine ${ }^{\circledR} 3118$ ) was kindly provided by Novacyl (Lyon, France).

\subsection{Statistics}

Data were expressed as mean \pm SEM, where $n$ is both the number of arterial segments studied and animal used. Data were analyzed for normal distribution by Shapiro-Wilk test. Differences in responses between groups were determined by two-way ANOVA, as indicated in figure legends. $p$ values $\leq 0.05$ were considered statistically significant.

\section{Conclusions}

Our results provide an insight into the molecular mechanism underlying aspirin vasodilation of resistance MA, and suggest that aspirin may be beneficial for the pregnant cardiovascular system by lowering PVR and, therefore, blood pressure.

Author Contributions: Investigation, original draft, H.H.; investigation, data curating, T.T.; funding acquisition, validation, S.G.; conceptualization, methodology, supervision, writing-review and editing, M.M. All authors have read and agreed to the published version of the manuscript.

Funding: This study was supported by the grants European Union 7th Framework Programme-FP7 (ASPRE Project \# 601852); the Icelandic Research Fund (Rannís, no. 163369-051).

Institutional Review Board Statement: The study was conducted according to the guidelines of the Declaration of Helsinki, and approved by the Italian Ministry of Health (n.74/2018-PR).

Informed Consent Statement: Not applicable.

Conflicts of Interest: The authors declare no conflict of interest. 


\section{References}

1. Schrör, K. General aspects (History and Chemistry). In Acetylsalicylic Acid; Wiley-VCH: Weinheim, Germany, 2009 ; pp. 3-32.

2. Zhou, B.; Wang, Q.; Zhao, Z.; Feng, X. A Systematic Review of the Efficacy and Safety of Aspirin When Delivered at Different Medication Times for the Primary and Secondary Prevention of Cardiovascular and Cerebrovascular Diseases. Innov. Regul. Sci. 2020, 54, 1339-1348. [CrossRef]

3. Rolnik, D.L.; Wright, D.; Poon, L.C.; O'Gorman, N.; Syngelaki, A.; de Paco Matallana, C.; Akolekar, R.; Cicero, S.; Janga, D.; Singh, M.; et al. Aspirin versus Placebo in Pregnancies at High Risk for Preterm Preeclampsia. N. Engl. J. Med. 2017, 377, 613-622. [CrossRef]

4. Walsh, S.W.; Strauss, J.F., 3rd. The Road to Low-Dose Aspirin Therapy for the Prevention of Preeclampsia Began with the Placenta. Int. J. Mol. Sci. 2021, 22, 6985. [CrossRef] [PubMed]

5. Backes, C.H.; Markham, K.; Moorehead, P.; Cordero, L.; Nankervis, C.A.; Giannone, P.J. Maternal preeclampsia and neonatal outcomes. J. Pregnancy 2011, 2011, 214365. [CrossRef] [PubMed]

6. Amaral, L.M.; Wallace, K.; Owens, M.; LaMarca, B. Pathophysiology and Current Clinical Management of Preeclampsia. Curr. Hypertens Rep. 2017, 19, 61. [CrossRef]

7. Bujold, E.; Roberge, S.; Lacasse, Y.; Bureau, M.; Audibert, F.; Marcoux, S.; Forest, J.C.; Giguere, Y. Prevention of Preeclampsia and Intrauterine Growth Restriction with Aspirin Started in Early Pregnancy: A Meta-Analysis. Obstet. Gynecol. 2010, 116, 402-414. [CrossRef] [PubMed]

8. Roberge, S.; Bujold, E.; Nicolaides, K.H. Aspirin for the prevention of preterm and term preeclampsia: Systematic review and metaanalysis. Am. J. Obs. Gynecol. 2018, 218, 287-293.e1. [CrossRef] [PubMed]

9. Haapsamo, M.; Martikainen, H.; Rasanen, J. Low-dose aspirin reduces uteroplacental vascular impedance in early and mid gestation in IVF and ICSI patients: A randomized, placebo-controlled double-blind study. Ultrasound Obstet. Gynecol. 2008, 32, 687-693. [CrossRef] [PubMed]

10. Kovo, M.; Rubinchik-Stern, M.; Miremberg, H.; Luria, O.; Bliecher, I.; Mizrachi, Y.; Bar, J. The effect of aspirin on placental vessels reactivity using the ex-vivo placental perfusion model. Thromb. Res. 2018, 170, 84-86. [CrossRef] [PubMed]

11. Ying, Z.K.; Giachini, F.R.C.; Tostes, R.C.; Webb, R.C. Salicylates dilate blood vessels through inhibiting PYK2-mediated RhoA/Rhokinase activation. Cardiovasc. Res. 2009, 83, 155-162. [CrossRef]

12. von der Weid, P.Y.; Hollenberg, M.D.; Fiorucci, S.; Wallace, J.L. Aspirin-triggered, cyclooxygenase-2-dependent lipoxin synthesis modulates vascular tone. Circulation 2004, 110, 1320-1325. [CrossRef] [PubMed]

13. Helgadottir, H.; Tropea, T.; Gizurarson, S.; Mandala, M. Aspirin causes endothelium-dependent vasodilation of resistance arteries from non-gravid and gravid rats. Pregnancy Hypertens 2019, 15, 141-145. [CrossRef] [PubMed]

14. Hermida, R.C.; Ayala, D.E.; Calvo, C.; Lopez, J.E. Aspirin administered at bedtime, but not on awakening, has an effect on ambulatory blood pressure in hypertensive patients. J. Am. Coll. Cardiol. 2005, 46, 975-983. [CrossRef] [PubMed]

15. Leithäuser, B.; Mrowietz, C.; Park, J.W.; Jung, F. Influence of acetylsalicylic acid (Aspirin) on cutaneous microcirculation. Clin. Hemorheol. Microcirc. 2012, 50, 25-34. [CrossRef] [PubMed]

16. Osol, G.; Ko, N.L.; Mandalà, M. Plasticity of the Maternal Vasculature During Pregnancy. Annu. Rev. Physiol. 2019, 81, 89-111. [CrossRef]

17. Lo Presti, D.; Scala, R.L.; Tiralongo, G.M.; Pisani, I.; Gagliardi, G.; Novelli, G.P.; Vasapollo, B.; Andreoli, A.; Valensise, H. Assessment of total vascular resistance and total body water in normotensive women during the first trimester of pregnancy in order to predict hypertensive complications. Pregnancy Hypertens. Int. J. Women's Cardiovasc. Health 2013, 3, 90-91. [CrossRef] [PubMed]

18. Khalil, R.A.; Granger, J.P. Vascular mechanisms of increased arterial pressure in preeclampsia: Lessons from animal models. Am. J. Physiol. Regul. Integr. Comp. Physiol. 2002, 283, R29-R45. [CrossRef]

19. Sandoo, A.; van Zanten, J.J.; Metsios, G.S.; Carroll, D.; Kitas, G.D. The endothelium and its role in regulating vascular tone. Open Cardiovasc. Med. J. 2010, 4, 302-312. [CrossRef]

20. Krüger-Genge, A.; Blocki, A.; Franke, R.P.; Jung, F. Vascular Endothelial Cell Biology: An Update. Int. J. Mol. Sci. $2019,20,4411$. [CrossRef]

21. Roberts, J.M. Endothelial dysfunction in preeclampsia. Semin. Reprod. Endocrinol. 1998, 16, 5-15. [CrossRef]

22. Ohlmann, P.; Jung, F.; Mrowietz, C.; Alt, T.; Alt, S.; Schmidt, W. Peripheral microcirculation during pregnancy and in women with pregnancy induced hypertension. Clin. Hemorheol. Microcirc. 2001, 24, 183-191.

23. Pelland, A.; George, R.B.; Lehmann, C.; Coolen, J. Sidestream Dark Field Imaging of the Microcirculation to Assess Preeclampsia Microvascular Dysfunction. J. Clin. Med. Res. 2018, 10, 391-395. [CrossRef]

24. Klabunde, R.E. Cardiovascular Physiology Concepts, 3rd ed.; Wolters Kluwer: The Alfven am Rhein, The Netherlands, 2021; ISBN 9781975150075.

25. Takala, J. Determinants of splanchnic blood flow. Br. J. Anaesth. 1996, 77, 50-58. [CrossRef]

26. Kim, T.H.; Weiner, C.P.; Thompson, L.P. Effect of pregnancy on contraction and endothelium-mediated relaxation of renal and mesenteric arteries. Am. J. Physiol. 1994, 267 Pt 2, H41-H47. [CrossRef]

27. Nelson, S.H.; Steinsland, O.S.; Suresh, M.S.; Lee, N.M. Pregnancy augments nitric oxide-dependent dilator response to acetylcholine in the human uterine artery. Hum. Reprod. 1998, 13, 1361-1367. [CrossRef] [PubMed] 
28. Luksha, L.; Nisell, H.; Luksha, N.; Kublickas, M.; Hultenby, K.; Kublickiene, K. Endothelium-derived hyperpolarizing factor in preeclampsia: Heterogeneous contribution, mechanisms, and morphological prerequisites. Am. J. Physiol. Regul. Integr. Comp. Physiol. 2008, 294, R510-R519. [CrossRef] [PubMed]

29. Barthelmes, J.; Nägele, M.P.; Ludovici, V.; Ruschitzka, F.; Sudano, I.; Flammer, A.J. Endothelial dysfunction in cardiovascular disease and Flammer syndrome-similarities and differences. EPMA J. 2017, 8, 99-109. [CrossRef]

30. Tuzcu, Z.B.; Asicioglu, E.; Sunbul, M.; Ozben, B.; Arikan, H.; Koc, M. Circulating endothelial cell number and markers of endothelial dysfunction in previously preeclamptic women. Am. J. Obstet. Gynecol. 2015, 213, 533.e1-533.e17. [CrossRef] [PubMed]

31. Sánchez-Aranguren, L.C.; Prada, C.E.; Riaño-Medina, C.E.; Lopez, M. Endothelial dysfunction and preeclampsia: Role of oxidative stress. Front. Physiol. 2014, 5, 372. [CrossRef] [PubMed]

32. Maynard, S.; Epstein, F.H.; Karumanchi, S.A. Preeclampsia and angiogenic imbalance. Annu. Rev. Med. 2008, 59, 61-78. [CrossRef]

33. Crews, J.K.; Herrington, J.N.; Granger, J.P.; Khalil, R.A. Decreased endothelium-dependent vascular relaxation during reduction of uterine perfusion pressure in pregnant rat. Hypertension 2000, 35 Pt 2, 367-372. [CrossRef]

34. Hecker, M.; Bara, A.T.; Bauersachs, J.; Busse, R. Characterization of EDHF as a cytochrome P450-derived arachidonic acid metabolite in mammals. J. Physiol. 1994, 481, 407-414. [CrossRef] [PubMed]

35. Sandow, S.L.; Tare, M.; Coleman, H.A.; Hill, C.E.; Parkington, H.C. Involvement of myoendothelial gap junctions in the actions of endothelium-derived hyperpolarizing factor. Circ. Res. 2002, 90, 1108-1113. [CrossRef]

36. Edward, G.; Dora, K.A.; Gardener, M.J.; Garland, C.J.; Weston, A.H. K ${ }^{+}$is an endothelium-derived hyperpolarizing factor in rat arteries. Nature 1998, 396, 269-272. [CrossRef] [PubMed]

37. Grgic, I.; Kaistha, B.P.; Hoyer, J.; Kohler, R. Endothelial $\mathrm{Ca}^{2+}$-activated $\mathrm{K}^{+}$channels in normal and impaired EDHF-dilator responses-relevance to cardiovascular pathologies and drug discovery. Br. J. Pharmacol. 2009, 157, 509-526. [CrossRef] [PubMed]

38. Hilgers, R.H.; Todd, J.J.R.; Webb, R.C. Regional heterogeneity in acetylcholine-induced relaxation in rat vascular bed: Role of calcium-activated K+ channels. Am. J. Physiol. Heart Cir. Physiol. 2006, 291, H216-H222. [CrossRef] [PubMed]

39. Mandalà, M.; Gokina, N.; Barron, C.; Osol, G. Endothelial-derived hyperpolarization factor (EDHF) contributes to PLGF-induced dilation of mesenteric resistance arteries from pregnant rats. J. Vasc. Res. 2012, 49, 43-49. [CrossRef] [PubMed]

40. Colton, I.; Mandalà, M.; Morton, J.; Davidge, S.T.; Osol, G. Influence of constriction, wall tension, smooth muscle activation and cellular deformation on rat resistance artery vasodilator reactivity. Cell. Physiol. Biochem. 2012, 29, 883-892. [CrossRef] [PubMed] 